\title{
Comparison of the Efficacy of Massage and Aromatherapy Massage With Geranium on Depression in Postmenopausal Women:A Clinical Trial
}

\author{
Seyed Maryam Lotfipur Rafsanjani ${ }^{1}$; Reza Vazirinejad ${ }^{2, *}$; Shayesteh Ismailzadeh ${ }^{1}$; Ali Ansari \\ Jaberi $^{3}$; Reza Bekhradi ${ }^{4}$; Ali Ravari ${ }^{5}$; Jafar Akbari ${ }^{6}$ \\ ${ }^{1}$ Department of Midwifery, Faculty of Nursing and Midwifery, Rafsanjan University of Medical Sciences, Rafsanjan, IR Iran \\ ${ }^{2}$ Department of Epidemiology, Social Determinants of Health Research Center, Rafsanjan University of Medical Sciences, Rafsanjan, IR Iran \\ ${ }^{3}$ Department of Psychiatric Nursing, Faculty of Nursing and Midwifery, Rafsanjan University of Medical Sciences, Rafsanjan, IR Iran \\ ${ }_{5}^{4}$ Department of Research, Barij Essence Pharmaceutical Company, Mashhad, IR Iran \\ 5 Department of Research, Barij Essence Pharmaceutical Company, Mashhad, IR Iran \\ ${ }^{6}$ Department of Nursing, Geriatric Care Research Center, Faculty of Nursing and Midwifery,
Department of Public Health, Rafsanjan University of Medical Sciences, Rafsanjan, IR Iran \\ ${ }^{*}$ Corresponding author: Reza Vazirinejad, Department of Epidemiology, Social Determinants of Health Research Center, Rafsanjan University of Medical Sciences, Rafsanjan, IR Iran. \\ E-mail: rvazirinejad@yahoo.co.uk
}

Received: November 9, 2013; Accepted: February 20, 2014

Background: Depression exacerbates the physical problems in menopause in addition to influencing the individual, occupational and social functioning of women.

Objectives: This study was conducted to determine the effect of aromatherapy massage on depression in menopausal women.

Patients and Methods: In this clinical trial, 120 menopausal women were selected based on the inclusion criteria and were randomly divided into three groups namely control, aromatherapy massage and massage group. Data collection tool in this study was demographics questionnaire and the Beck Depression Inventory (BDI). In aromatherapy massage group, essential oil of geranium (2\%) in almond oil was used. Both groups were treated for 8 weeks, once a week for 30 minutes and their depression rate was assessed before and after the intervention and were compared with the control group. ANOVA and t-test were used for data analysis.

Results: Aromatherapy massage reduced the mean depression score (MD: 0.51, 95\%CI). Massage therapy also reduced depression score (MD: $0.20,95 \% \mathrm{CI})(\mathrm{P}<0.001)$. To detect the effects of aromatherapy and massage therapy separately, the mean depression score was compared and aromatherapy massage reduced the depression score more than massage therapy (MD:-0.31, 95\%CI).

Conclusions: The results of this study consider aromatherapy massage beneficial in improving symptoms of depression and recommend it as a complementary therapy.

Keywords: Aromatherapy; Depression; Massage; Menopause

\section{Background}

With the increase in life expectancy within the next 25 years, more than one billion women in the world will reach the age of menopause [1]. In this stage, due to estrogen deficiency, in addition to numerous physical problems $[1,2]$ women might be susceptible to insomnia, irritability and depression that may lead to exacerbation of menopausal physical problems [3, 4]. Several studies showed that physiological symptoms of menopause have more intensity in women who suffer from depression [5-7]. The use of hormone replacement therapy (HRT) for treating menopause symptoms and complications accompanies some potential risks such as increased risk of heart attack and breast cancer [8, 9]. Many women have contraindications for hormone therapy due to underlying conditions [10]. Therefore, the use of alternative or complementary therapies that can improve menopausal symptoms with minimal side effects seem necessary, one of these treatments is to massage with solutions and aro- matic essential oils or aromatherapy [11-14]. During aromatherapy, essential oils are absorbed through the skin or through nasal inhalation during massage and after entering the bloodstream via the nervous system, they exert their effect [15]. Among the essential oils found in nature, lavender, rose, sweet orange and geranium have anti-anxiety and anti-depression effects [12, 16-18]. Geranium, Pelargonium graveolens, is a herbaceous plant with an essential oil extracted from its leaves. It stimulates the adrenal cortex and is used in diseases in which hormonal balance is necessary [17]. Hur et al. investigated the effects of aromatherapy massage on menopausal symptoms and showed that aromatherapy massage had a positive effect on vasomotor symptoms, myalgia and arthralgia, but its effect on symptoms such as hot flashes and depression were controversial and needed further studies [19]. Taavoni et al. investigated the effect of aromatherapy massage on physiological symptoms of menopause

Copyright (C) 2015, Zahedan University of Medical Sciences. This is an open-access article distributed under the terms of the Creative Commons Attribution-NonCommercial 4.0 International License (http://creativecommons.org/licenses/by-nc/4.0/) which permits copy and redistribute the material just in noncommercial usages, provided the original work is properly cited. 
and showed that aromatherapy massage is effective on symptoms such as physical fatigue, irritability, anxiety and depressed mood [20]. Other studies also investigated anxiety [16], pain [21, 22] and sleep [12] of patients, but no studies have assessed the effect of aromatherapy massage specifically on depression in menopausal women. Furthermore, Kuriyama et al. have questioned the effect of aromatherapy massage on depression and suggested further studies in this regard [23]. Complementary therapies, such as massage and aromatherapy have been known as low risk, cost-effective, easy and with few side effects [24].

\section{Objectives}

Since the effect of aromatherapy massage in the treatment of depression is not known well, researchers intend to investigate the effect of aromatherapy massage on depression in menopausal women in order to find a low risk way of reducing the complications of this stage.

\section{Patients and Methods}

In this clinical trial, of postmenopausal women who attended the health center, 120 women suffering from depression that got a score of 14 or above based on the Beck Depression Inventory (BDI) were divided randomly into three groups namely; aromatherapy massage group, massage therapy group and the control group. It means out of every three postmenopausal women with depression, one was placed in aromatherapy massage, one in the massage group and one in the control group. Inclusion criteria were the following: being older than 45 years old, at least one year passed from their amenorrhea, not having a history of dysplasia or cervical, endometrial and breast cancer, not having a history of taking antidepressants and hormone therapy in the past three months, agreeing with aromatherapy massage, not having allergy to aromatherapy (checking was through the skin test before starting aromatherapy). Exclusion criteria were as follows: allergy to aromatherapy during the study, starting hormone therapy or antidepressant treatment during the study, the occurrence of any crisis such as a death in the family during the study, absence of more than two sessions from aromatherapy. Each person in aromatherapy massage group received a 30-minute session of aromatherapy massage per week for 8 weeks (a total of 8 sessions). Treatment included massaging with geranium oil (2\%) in almond oil. Geranium oil was made from the aerial parts of the plant and was prepared by using hydrodistillation method in Barij Essence pharmaceutical company (Mashhad, Iran). In massage therapy group, the participants received a 30 min massage per week only with sweet almond oil for 8 weeks duration. The control group was controlled once a week regarding their general condition and taking probable medication. To do the aromatherapy massage, 4 experienced midwives who were experienced in mother-child care, were selected and trained. In order to make an identical environmental condition and temperature, the massage was performed in a room having a temperature of between $24^{\circ} \mathrm{C}$ and $26^{\circ} \mathrm{C}$ and on a certain day of the week. The skin allergy test was also done and in case of any allergic reaction, the subject was excluded. The participants were recommended to report any specific changes in their lives, where they were excluded if that change could affect the study such as taking a new medication (anti-depressant medication). The massage was done using effleurage method for both groups and each session, $10 \mathrm{~mL}$ of oil was gradually used on abdomen, back and arms. The massage in effleurage method is with light, rhythmic and gentle rubbing movements at lower abdomen in the form of circular stroking movements toward left and right. This massage is done with the palm of the hand or fingers and without pressure. In general, if we consider the intensity of the given pressure between 1 and 10 , in this massage the given pressure is equal to 4 , while massaging the abdomen, a pillow is placed under the knees so that the abdomen would be without contraction (relax). At the end of study, BDI questionnaire was completed again. For participants' convenience, massage was done in a room with a closed door having a window with a curtain and during the massage no one was allowed to enter the room. Participants could use sheet during the massage and they were assured that their personal information would remain confidential. The number of participants after completing BDI was 40 in aromatherapy group, 38 in the massage group and 40 in the control group. During the study, no side effect such as allergy occurred. BDI is a self-report questionnaire that generally includes 21 items related to different symptoms and the participants should respond based on a four-point scale from 0 to 3 . The questions are in areas such as sadness, pessimism, feeling of inability and failure, guilt, sleep disturbance, loss of appetite, self-loathing etc. Thus, 2 questions are related to emotion, 11 questions to cognition, 2 questions to apparent behaviors, 5 questions to physical symptoms and 1 question to interpersonal relationship. Therefore, this scale determines the various depression degrees from mild to severe and its scores range between zero and 63 . In this study, researchers used aromatherapy for mild and moderate depressions and the women with severe depression were referred to a psychiatrist. Various studies have been conducted regarding the validity of BDI as well. Among these studies, Tashakori and Mehryar study can be mentioned which calculated a reliability coefficient of 0.78 in Iran [25]. The collected data were assessed in SPSS 12 software using ANOVA statistical tests and independent sample t-test for comparing between groups, and paired sample t-test for before-after comparison at significance level of $\mathrm{P}<0.05$. This clinical trial was approved by the ethics committee of Rafsanjan University of Medical Sciences (Reg. 9/20/1086) and was funded by this university. 


\section{Results}

In this study, 120 participants were divided into three groups of 40 participants. Two participants were excluded from the study before the end of the trial due to absence of more than two sessions and the analysis was ultimately performed on 118 participants: aromatherapy massage group $(n=40)$, massage group $(n=$ 38 ) and control group $(n=40)$ (Figure 1$)$. The mean and the standard deviation of the demographic variables of age, age at menarche, age at menopause and number of children are shown in Table 1 . The mean depression score according to BDI was not significantly different in the three groups before the experiment, while after eight sessions of intervention, a statistically significant difference was observed in depression scores of the participants in the case groups, while there was no statistical difference in the control group (Tables 2 and 3) (P $=0.001$ for aromatherapy massage group, $\mathrm{P}=0.001$ for massage group)

\section{Discussion}

The results of the present study confirm this theory that aromatherapy massage could reduce depression in menopause. In this study, the depression score of all the participants who received the eight session intervention was reduced significantly compared to the control group, however, this reduced depression score was more in aromatherapy massage group compared to massage therapy group. In Kuriyama et al. study, massaging only affected the anxiety score and did not change participants' depression score [23]

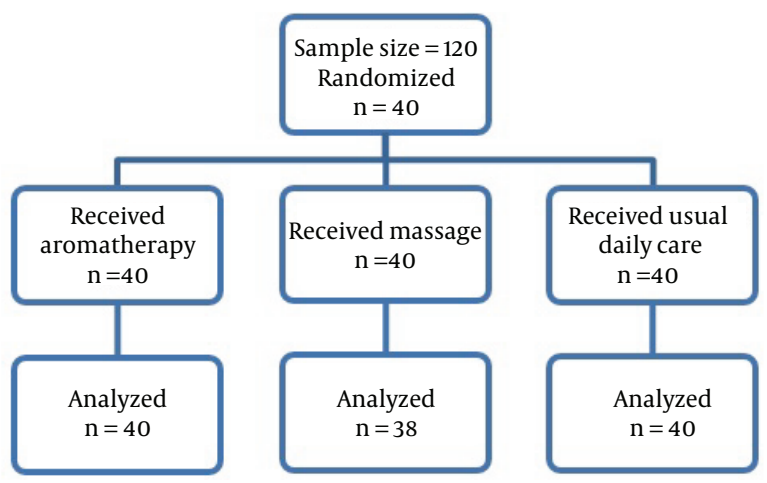

Figure 1. Randomization of Aromatherapy Massage Groups in Postmenopausal Women Suffering From Depression

Table 1. Demographic Variables of Participants in the Beginning of the Study ${ }^{\text {a }}$

\begin{tabular}{lccc}
\hline Characteristics & Aromatherapy Massage & Massage Therapy & Control \\
\hline Age, $\mathbf{y}$ & $54.80 \pm 4.58$ & $55.63 \pm 5.04$ & $54.78 \pm 4.82$ \\
Age of menarche, $\mathbf{y}$ & $11.83 \pm 1.29$ & $12.08 \pm 1.05$ & $11.85 \pm 1.00$ \\
Age at menopause, $\mathbf{y}$ & $50.43 \pm 1.59$ & $49.55 \pm 2.87$ & $50.15 \pm 1.99$ \\
Number of children & $4.65 \pm 2.16$ & $5.34 \pm 1.72$ & $4.80 \pm 2.40$ \\
\hline
\end{tabular}

a Data are presented as No. (\%).

Table 2. Measuring Effects of Aromatherapy Massage and Massage Therapy on Depression

\begin{tabular}{lcccc}
\hline & Before $^{\mathrm{a}}$ & After $^{\mathrm{a}}$ & Mean Difference 95\%CIS $^{\text {P-Value }}$ \\
\hline Aromatherapy massage & $1.01 \pm 0.19$ & $0.5 \pm 0.17$ & 0.51 & 0.001 \\
Massage therapy & $1.01 \pm 0.22$ & $0.81 \pm 0.15$ & 0.20 & 0.001 \\
Control & $1.00 \pm 0.16$ & $1.00 \pm 0.15$ & 0.00 & - \\
\hline
\end{tabular}

a Data are presented as Mean \pm SD.

Table 3. Comparison of depression rate in the two intervention groups ${ }^{a}$

\begin{tabular}{|c|c|c|c|c|c|}
\hline & \multirow[t]{2}{*}{ Aromatherapy Massage ${ }^{b}$} & \multirow[t]{2}{*}{ Massage Therapy ${ }^{b}$} & \multirow[t]{2}{*}{ Mean Difference } & \multicolumn{2}{|c|}{ 95\% CIS } \\
\hline & & & & Lower & Higher \\
\hline Paired difference & $0.50 \pm 0.17$ & $0.81 \pm 0.15$ & -0.31 & -0.38 & -0.23 \\
\hline
\end{tabular}


while in Hur et al. study, using aromatherapy massage with compounds containing geranium reduced the depression score of menopausal women like this study [19]. Moreover, results of Okamoto et al. study have also shown that aromatherapy massage with compounds containing geranium caused a reduction in depression score of the patients with mild depression [26]. The difference observed in the present study and Kuriyama's study may be due to the fact that in their study, the duration of aromatherapy was only 30 minutes and essential oils such lavender were used, whereas in the present study, aromatherapy was done eight times for 30 minutes each time, and geranium was used, which is mentioned in references for its antidepressant effect [23]. Most depression cases are associated with decreased brain metabolism and blood flow in frontal lobe [27]. Various studies indicated that the brain stimulation by scents increases the blood flow to the frontal lobe cortex $[26,28]$. Evidence shows that aromatherapy massage improves depression through improving the blood flow in the frontal cortex of the brain. This study showed that the group who received the massage had a lower depression score compared to the control group yet the effect of massage on depression was much less than aromatherapy massage. Massage therapy, by stimulating the body's soft tissues causes the restoring of metabolic balance and also reinforces a sense of caring and support and expression of love to the patient [21], therefore, it is expected that better results are gained when its positive effects are added to aromatherapy. No study was found that have examined the impact of massage alone on depression rate and most papers in this regard evaluated the effect of massage on pain and anxiety $[21,22]$. To know about this important issue indicates the need for doing further studies in this field. This study has the following limitations: 1- Researchers and massage therapists were aware of the type of treatment that was used for each group, 2- long-term effects were not investigated in the study. These limitations should be considered in future studies and more studies are required prior to presenting certain results. In general, this study reveals that both aromatherapy massage and massage improve depression symptoms in postmenopausal women by improving the brain's bloodstream and strengthening the care and support feeling. Since no side effects were expressed a month after treatment and participants were satisfied in that the people in aromatherapy massage asked for receiving geranium essential oil to massage themselves, therefore, aromatherapy massage with geranium essential oil can be used for depression in menopausal women as a complementary treatment (easy, economical and non-invasive).

\section{Acknowledgements}

We would like to appreciate the efforts of health care center personnel who helped us in data collection. Moreover,
Barij Essence Pharmaceutical Company is also appreciated for essential oil preparation. This trial was registered in Clinical Trial Center in Iran (IRCT138811061061N6).

\section{Authors' Contributions}

All authors had equal role in design, work, statistical analysis and manuscript writing.

\section{Funding/Support}

Rafsanjan University of Medical Sciences.

\section{References}

1. Whiteley J, Wagner JS, Bushmakin A, Kopenhafer L, Dibonaventura M, Racketa J. Impact of the severity of vasomotor symptoms on health status, resource use, and productivity. Menopause. 2013;20(5):518-24.

2. Cizza G. Major depressive disorder is a risk factor for low bone mass, central obesity, and other medical conditions. Dialogues Clin Neurosci. 2011;13(1):73-87.

3. Chen MH, Su TP, Li CT, Chang WH, Chen TJ, Bai YM. Symptomatic menopausal transition increases the risk of new-onset depressive disorder in later life: a nationwide prospective cohort study in Taiwan. PLoS One. 2013;8(3).

4. Bromberger JT, Kravitz HM. Mood and menopause: findings from the Study of Women's Health Across the Nation (SWAN) over 10 years. Obstet Gynecol Clin North Am. 2011;38(3):609-25.

5. Soares CN. Can depression be a menopause-associated risk? BMC Med. 2010;8:79.

6. Freeman EW, Sammel MD, Lin H. Temporal associations of hot flashes and depression in the transition to menopause. Menopause. 2009;16(4):728-34.

7. Joffe H, Soares CN, Thurston RC, White DP, Cohen LS, Hall JE. Depression is associated with worse objectively and subjectively measured sleep, but not more frequent awakenings, in women with vasomotor symptoms. Menopause. 2009;16(4):671-9.

8. Stram DO, Liu Y, Henderson KD, Sullivan-Halley J, Luo J, Saxena T, et al. Age-specific effects of hormone therapy use on overall mortality and ischemic heart disease mortality among women in the California Teachers Study. Menopause. 2011;18(3):253-61.

9. Lisabeth L, Bushnell C. Stroke risk in women: the role of menopause and hormone therapy. Lancet Neurol . 2012;11(1):82-91.

10. Berek JS. Berek \& Novak's gynecology. 15th. ed.Philadelphia: Lippincott Williams \& Wilkins; 2012.

11. Zhang M, Sun S, Tang N, Cai W, Qian L. Oral administration of alkylglycerols differentially modulates high-fat diet-induced obesity and insulin resistance in mice. Evid Based Complement Alternat Med. 2013;2013:834027.

12. Cho MY, Min ES, Hur MH, Lee MS. Effects of aromatherapy on the anxiety, vital signs, and sleep quality of percutaneous coronary intervention patients in intensive care units. Evid Based Complement Alternat Med. 2013;2013:381381.

13. Ju MS, Lee S, Bae I, Hur MH, Seong K, Lee MS. Effects of aroma massage on home blood pressure, ambulatory blood pressure, and sleep quality in middle-aged women with hypertension. Evid Based Complement Alternat Med. 2013;2013:7.

14. Conrad P, Adams C. The effects of clinical aromatherapy for anxiety and depression in the high risk postpartum woman - a pilot study. Complement Ther Clin Pract. 2012;18(3):164-8.

15. Mahmoudi B. [Essential oils and their healing effects]. persian.Tehran: Noor-e-Danesh Press; 2004.

16. Imanishi J, Kuriyama H, Shigemori I, Watanabe S, Aihara Y, Kita M, et al. Anxiolytic effect of aromatherapy massage in patients with breast cancer. Evid Based Complement Alternat Med. 2009;6(1):123-8.

17. Zargari A. [Iran medical plant]. persian.Tehran: Tehran University Press; 1991.

18. Fonareva I, Demidenko M, Oken B. P02.102. Evaluating the role of 


\section{Lotfipur Rafsanjani SM et al.}

expectancy during stress-reducing aromatherapy in healthy older adults. Evid Based Complement Alternat Med. 2012;12(Suppl 1):P158.

19. Hur MH, Yang YS, Lee MS. Aromatherapy massage affects menopausal symptoms in korean climacteric women: a pilotcontrolled clinical trial. Evid Based Complement Alternat Med. 2008;5(3):325-8.

20. Taavoni S, Darsareh F, Joolaee S, Haghani H. The effect of aromatherapy massage on the psychological symptoms of postmenopausal Iranian women. Complement Ther Med. 2013;21(3):158-63.

21. Yegane Khah M, Shah Balaghi F, Khankeh H, Rahgozar M. Effect of back stroke massage on adult anxiety. Rehabil J. 2009;8(3):14-20.

22. Mok E, Woo CP. The effects of slow-stroke back massage on anxiety and shoulder pain in elderly stroke patients. Complement Ther Nurs Midwifery. 2004;10(4):209-16.

23. Kuriyama H, Watanabe S, Nakaya T, Shigemori I, Kita M, Yoshida $\mathrm{N}$, et al. immunological and psychological benefits of aromatherapy massage. Evid Based Complement Alternat Med.
2005;2(2):179-84.

24. Duncan AD, Liechty JM, Miller C, Chinoy G, Ricciardi R. Employee use and perceived benefit of a complementary and alternative medicine wellness clinic at a major military hospital: evaluation of a pilot program. J Altern Complement Med. 2011;17(9):809-15.

25. Azkhosh M. Application of mental tests and clinical diagnosis. 3th edTehran: Ravan Press; 2010.

26. Okamoto A, Kuriyama H, Watanabe S, Aihara Y, Tadai T, Imanish J, et al. The effect of aromatherapy massage on mild depression: a pilot study. Psychiatry Clin Neurosci. 2005;59(3):363.

27. Moreaud O, Naegele B, Chabannes JP, Roulin JL, Garbolino B, Pellat J. [Frontal lobe dysfunction and depressive state: relation to endogenous character of depression]. franch. Encephale. 1996;22(1):47-51.

28. Hirata K. The cecrebral blood flow change by fragrance-An evaluation using near-infrared spectroscopic topography. Jpn J Pharmaco EEG. 2002;4:43-7. 